\title{
Estudo do desenvolvimento de couve manteiga (Brassica oleracea L.) a partir da germinação em resposta as fontes de variação
}

\author{
Study of the development of kale (Brassica oleracea $L_{\text {. }}$ ) from germination in response as sources of \\ variation
}

Estudio del desarrollo de la col rizada (Brassica oleracea L.) a partir de la germinación en respuesta como fuentes de variación

Recebido: 27/08/2021 | Revisado: 07/09/2021 | Aceito: 10/09/2021 | Publicado: 12/09/2021

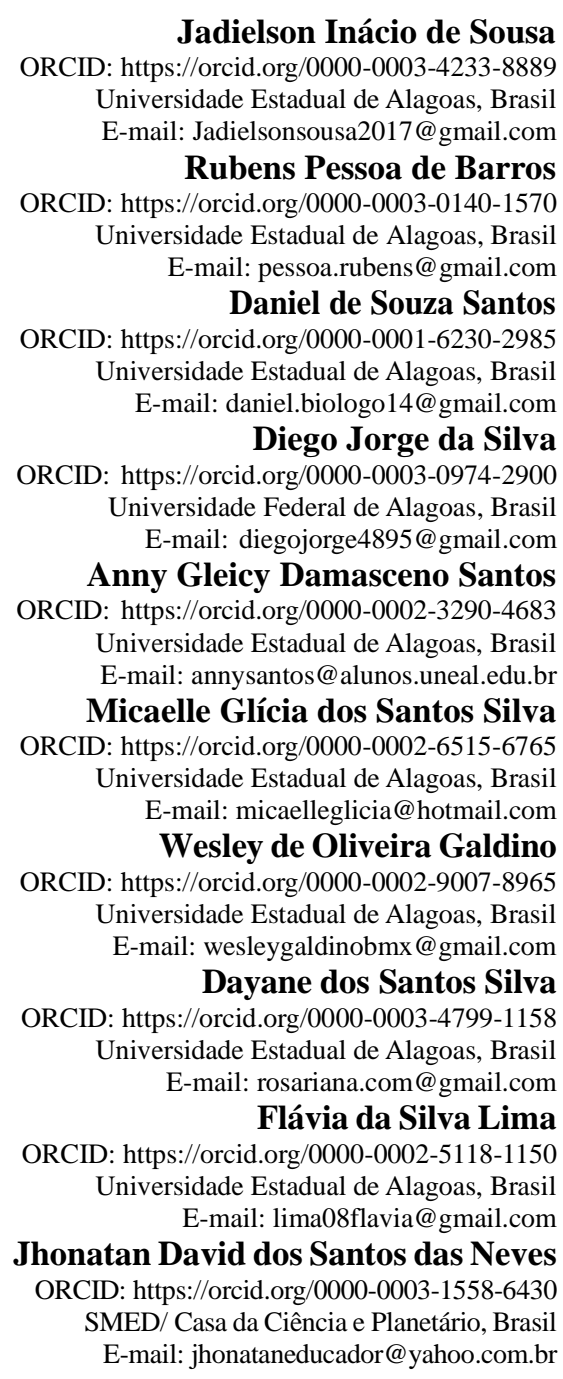

\section{Resumo}

A couve manteiga da Geórgia (Brassica oleracea L. var. acephala) é uma hortaliça pertencente à família Brassicaceae, arbustiva anual ou bienal, cujo consumo no Brasil tem aumentado devido às novas pesquisas de suas propriedades nutricionais. O objetivo desse estudo foi acompanhar o desenvolvimento da couve a partir da germinação nas causas de variação. O estudo experimental foi conduzido na casa de vegetação da Universidade Estadual de Alagoas campus I durante os meses de outubro a dezembro de 2020. As sementes usadas para o cálculo de índice de germinação (IG) e índice de velocidade de germinação (IVG) foram semeadas em sementeira utilizando o substrato de casca de arroz carbonizada, foram utilizadas 96 células e 5 sementes em cada uma delas, totalizando 480 sementes. Nos vasos o delineamento experimental foi inteiramente casualizado, com quatro tratamentos e cinco repetições. As variáveis de pré-colheita avaliadas foram: altura da planta (AP), diâmetro do caule (DC) e o número de folhas (NF), já na pós- 
colheita: massa fresca (MF), massa seca (MS), tamanho da raiz (TR) e tamanho total (TT). O registro dos dados foi feito semanalmente e depois analisados estatisticamente, através do programa Agroestat para verificar a análise de variância - ANOVA e a comparação de médias, através do teste Tukey a $5 \%$ de probabilidade. A germinação apresentou bons resultados e houve diferença significativa entre os tratamentos, sendo o esterco caprino o que apresentou melhor resultado.

Palavras-chave: Couve; Germinação; Substratos.

\begin{abstract}
Georgian cabbage (Brassica oleracea L. var. acephala) is a vegetable belonging to the Brassicaceae family, an annual or biennial shrub, whose consumption in Brazil has increased due to new research on its nutritional properties. The aim of this study was to monitor the development of kale from germination in the causes of variation. The experimental study was conducted in the greenhouse of the State University of Alagoas campus I from October to December 2020. The seeds used to calculate the germination index (GI) and germination speed index (IVG) were sown. in sowing using carbonized rice husk substrate, 96 cells and 5 seeds were used in each, totaling 480 seeds. In pots, the experimental design was completely randomized, with four treatments and five replications. The pre-harvest variables evaluated were: plant height (HP), stem diameter (DC) and number of leaves (NF), in post-harvest: fresh mass (MF), dry mass (DM), size root (TR) and full size (TT). Data were recorded weekly and then statistically analyzed using the Agroestat program to verify the analysis of variance - ANOVA and the comparison of means, using the Tukey test at $5 \%$ probability. Germination showed good results and there was a significant difference between treatments, with goat manure showing the best result.
\end{abstract}

Keywords: Cabbage; Germination; Substrates.

\title{
Resumen
}

La col de Georgia (Brassica oleracea L. var. Acephala) es una hortaliza perteneciente a la familia Brassicaceae, un arbusto anual o bienal, cuyo consumo en Brasil ha aumentado debido a nuevas investigaciones sobre sus propiedades nutricionales. El objetivo de este estudio fue monitorear el desarrollo de la col rizada a partir de la germinación en las causas de variación. El estudio experimental se realizó en el invernadero de la Universidad Estatal de Alagoas campus I de octubre a diciembre de 2020. Las semillas utilizadas para calcular el índice de germinación (IG) y el índice de velocidad de germinación (IVG) se sembraron en siembra utilizando sustrato de cáscara de arroz carbonizado. Se utilizaron 96 células y 5 semillas en cada uno, totalizando 480 semillas. En macetas, el diseño experimental fue completamente al azar, con cuatro tratamientos y cinco repeticiones. Las variables pre-cosecha evaluadas fueron: altura de planta (HP), diámetro de tallo (DC) y número de hojas (NF), en post-cosecha: masa fresca (MF), masa seca (MS), tamaño raíz (TR) y tamaño completo (TT). Los datos se registraron semanalmente y luego se analizaron estadísticamente usando el programa Agroestat para verificar el análisis de varianza - ANOVA y la comparación de medias, usando la prueba de Tukey al 5\% de probabilidad. La germinación mostró buenos resultados y hubo una diferencia significativa entre los tratamientos, siendo el estiércol de cabra el mejor resultado.

Palabras clave: Repollo; Germinación; Sustratos.

\section{Introdução}

No mercado de hortaliças existem algumas variedades de couve produzidas e comercializadas, as que estão em produção no Brasil, são aquelas mais adaptadas às condições edafoclimáticas, Brassica oleracea se divide em tipos: Brassica oleracea var. acephala: a couve manteiga; Brassica oleracea var. capitata: o repolho, a couve vermelha, a couve de Milão; Brassica oleracea var. botytris: a couve-flor; Brassica oleracea var. italica: a couve-brócolis; Brassica oleracea var. gemmifera: a couve de Bruxelas; Brassica oleracea var. gongylodes: a couve-rábano e a Brassica oleracea var. alboglabra: a couve chinesa Kairan, Gai-lohn (Paraná, 2017).

A couve manteiga da Geórgia (B. oleracea L. var. acephala) é uma hortaliça pertencente à família Brassicaceae, arbustiva anual ou bienal, cujo consumo no Brasil tem aumentado devido às novas pesquisas de suas propriedades nutricionais e maneiras de utilização na culinária brasileira (Camargo Filho \& Camargo, 2009). A família Brassicaceae possui aproximadamente 4.000 espécies e cerca de 400 gêneros, encontra-se dentre aquelas com maior número de espécies do grupo das dicotiledôneas (Koch et al., 2001).

O homem precisa produzir alimentos para suprir e garantir a sua sobrevivência e a das gerações futuras, e a busca por um sistema produtivo mais sustentável vem ganhando forças como uma opção alternativa ao modelo dominante de produção de alimentos (Lunardon, 2008). 
De acordo com Bezerra Neto et al. (2010) o sucesso na produção de hortaliças inicia-se na fabricação de mudas, pois interferi diretamente no aspecto sanitário da cultura, na eficiência operacional, nos custos e na qualidade do produto final.

A utilização de substratos reúne diversas características que promovem a retenção de umidade do solo dependendo da disponibilidade da plântula e enriquece com seus nutrientes presentes em todos os substratos desenvolvendo melhores condições para o desenvolvimento da planta (Souza et al., 2014), em função da obtenção de resultados positivos, sua utilização na agricultura, tem crescido, havendo estudos que comprovam a eficácia deste tipo de adubação no cultivo de mudas de plantas frutíferas (Sousa et al., 2015). Segundo Linhares (2015) entre as fontes orgânicas de maior uso destacam-se os estercos. De acordo com Jordana Finatto et al. (2013) o uso de adubos orgânicos nos solos contribui para uma melhoria significativa de suas propriedades, sejam elas físicas, químicas ou biológicas, obtendo-se respostas positivas das plantas.

O objetivo desse estudo foi acompanhar o desenvolvimento de couve a partir da germinação nas causas de variação.

\section{Metodologia}

\subsection{Local de pesquisa}

Trata-se de uma pesquisa experimental realizada dentro da casa de vegetação da Universidade Estadual de Alagoas Campus I (Figura 1), de janeiro a dezembro de 2020, na latitude $09^{\circ} 45^{\prime} 09^{\prime}$ ' S, longitude $36^{\circ} 39^{\prime} 40^{\prime}$ ' W, altitude $264 \mathrm{~m}$. O clima da região é do tipo As', determinando o clima tropical e quente segundo a classificação de Köppen Geiger (1928).

A pesquisa metodológica foi baseada em Silva et al. (2017) e Santos et al. (2019) os quais abordam a pesquisa realizada como uma forma de organização de dados monitorados para realização de estudos estatísticos. Os estudos norteadores da parte experimental foram adaptados de Cabral et al. (2019).

Figura 1. Local de realização da pesquisa.

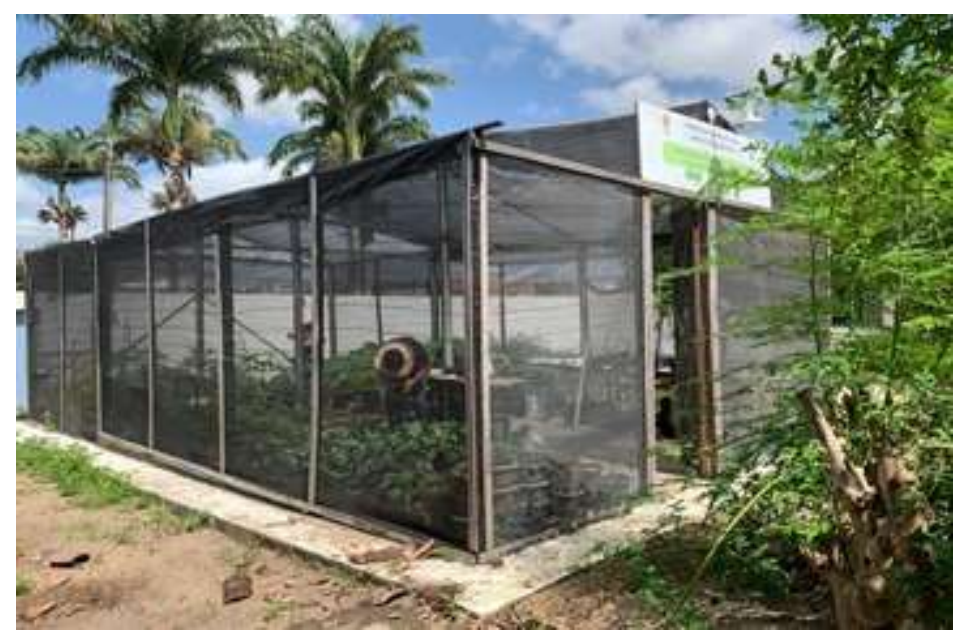

Fonte: Autores.

\subsection{Procedimentos metodológicos}

As sementes usadas para o cálculo de índice de germinação (IG) e índice de velocidade de germinação (IVG) foram semeadas em sementeira de isopor (Figura 2) utilizando o substrato de casca de arroz carbonizada, foram utilizadas 96 células e 5 sementes em cada uma delas, totalizando 480 sementes. 
Figura 2. Germinação da couve (B. oleracea L.) na sementeira.

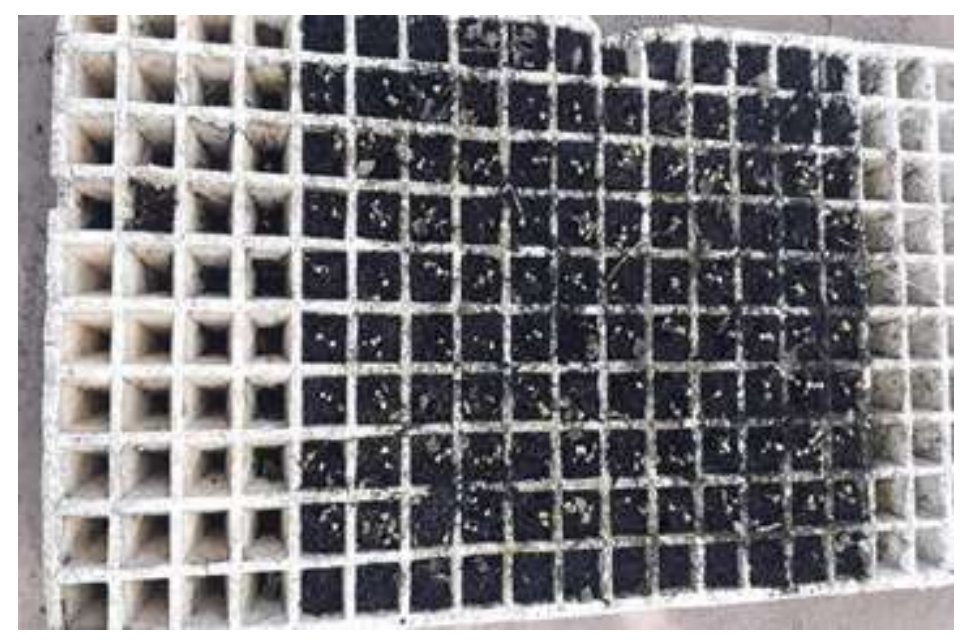

Fonte: Autores.

Ao iniciar as germinações os dados foram coletados e registrados em uma planilha do Excel para análise de IG (índice de germinação) (1) e IVG (índice de velocidade de germinação) (2) onde foram utilizadas as seguintes fórmulas:

$$
I G=\frac{G .100 \%}{N}
$$

Em que: $\mathrm{G}=$ número total de plântulas germinadas, e $\mathrm{N}$ = número total de sementes.

$$
I V G=\frac{G 1}{N 1}+\frac{G 2}{N 2}+\cdots \frac{G n}{N n}
$$

Em que: G1, G2 e Gn = número de plântulas na primeira, na segunda e na última contagem, e N1, N2 e N3 = número de dias após a semeadura na primeira, na segunda e na última contagem. Para a análise fenológica, o monitoramento da couve (Brassica oleracea L.) foi realizado durante os meses de outubro a dezembro de 2020, a semeadura foi feita diretamente em 20 vasos plásticos com 5 sementes em cada.

O delineamento experimental foi o inteiramente casualizado, foram utilizados quatro tratamentos com 3 partes de solo e 1 de esterco, sendo eles, solo mais substrato organomineral (T1), solo mais esterco aviário (T2), solo mais esterco bovino (T3) e solo mais esterco caprino (T4). O desbaste foi realizado 20 dias após a semeadura, onde foi deixada apenas a planta aparentemente mais vigorosa (Figura 3). 
Figura 3. Couve (B. oleracea L.) após desbaste.

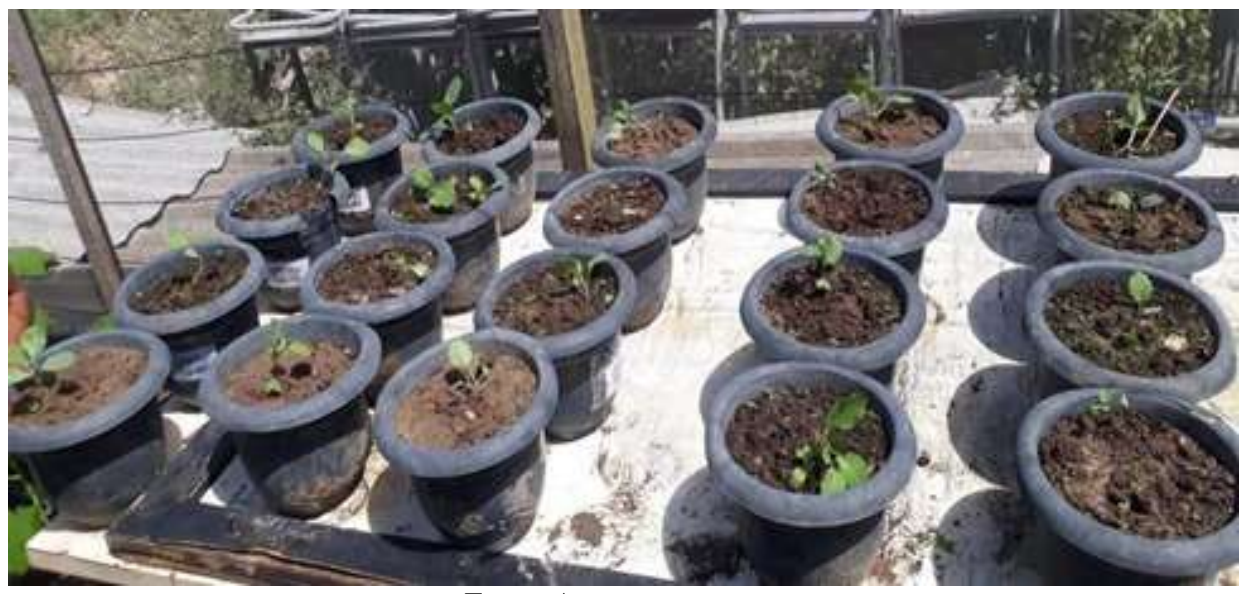

Fonte: Autores.

As variáveis de pré-colheita avaliadas foram: altura da planta (AP), diâmetro do caule (DC) e o número de folhas (NF). Na pós-colheita (Figura 4) as variáveis foram: massa fresca (MF), massa seca (MS), tamanho da raiz (TR) e tamanho total (TT).

Figura 4. Retirada da couve (B. oleracea L.) dos vasos.

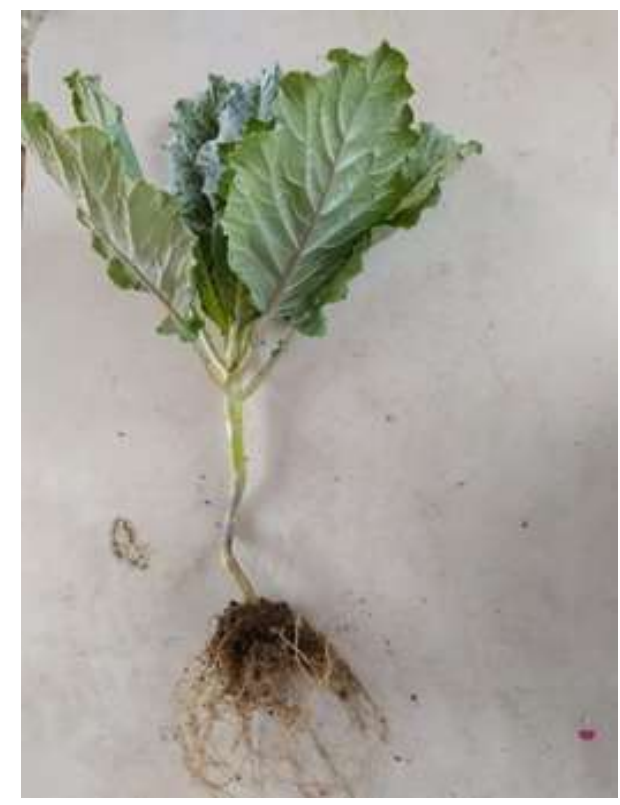

Fonte: Autores.

\subsection{Análise de dados}

O registro dos dados foi feito semanalmente sendo tabelados em planilhas do Excel para posteriormente serem analisados estatisticamente, através do programa Agroestat (MALDONADO JR., 2021) para verificar a ANOVA- análise de variância e a comparação de médias através do teste de Tukey a 5\% de probabilidade.

\section{Resultados e Discussão}

A germinação das sementes de couve iniciou-se no segundo dia após a semeadura, ao sétimo dia observou-se que as sementes expressaram todo seu potencial de germinação. Os Índices de Germinação (IG) e o Índice de Velocidade de Germinação (IVG) da couve são verificados na figura 5 e 6 . Conforme o índice de determinação $\left(\mathrm{R}^{2}\right)$, para o $\mathrm{IG}$ foi de $\mathrm{R}^{2}=$ 
0,60, para o IVG o R2 = 0,70. Saidelles et al., (2009) concluiu em sua pesquisa que a casca de arroz carbonizada utilizada em diferentes proporções influenciou significativamente nos índices de qualidade de mudas de Enterolobium contortisiliquum e Apuleia leiocarpa.

Figura 5. Índice de germinação da couve (B. oleracea L.).

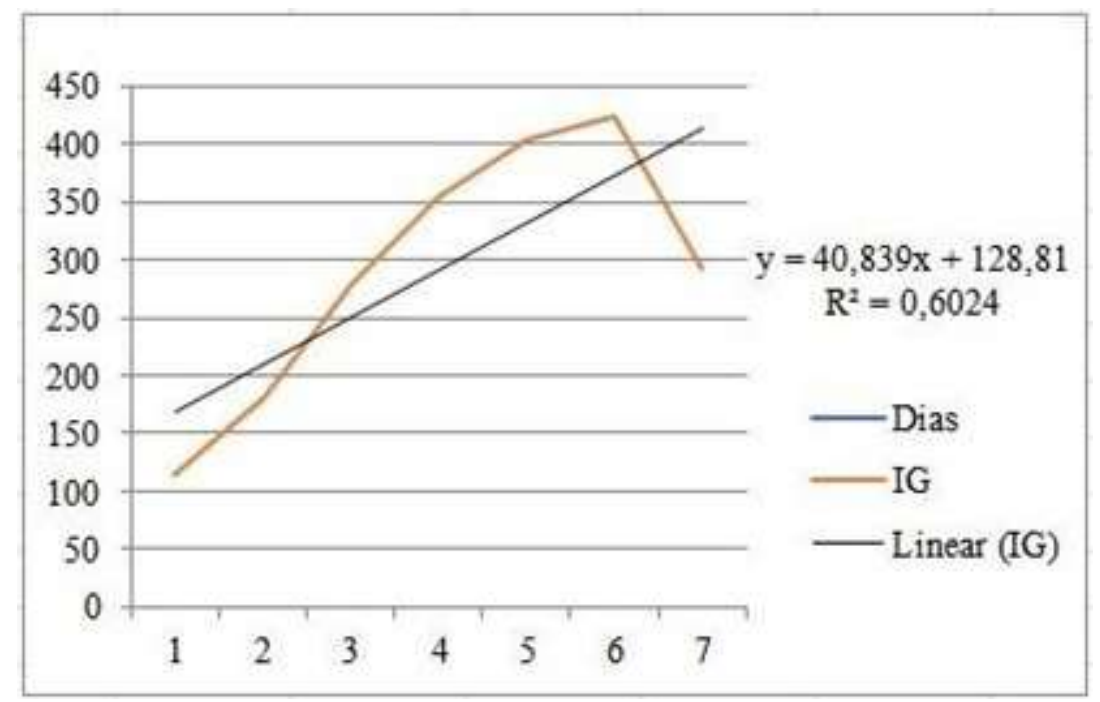

Fonte: Autores.

Figura 6. Índice de velocidade de germinação.

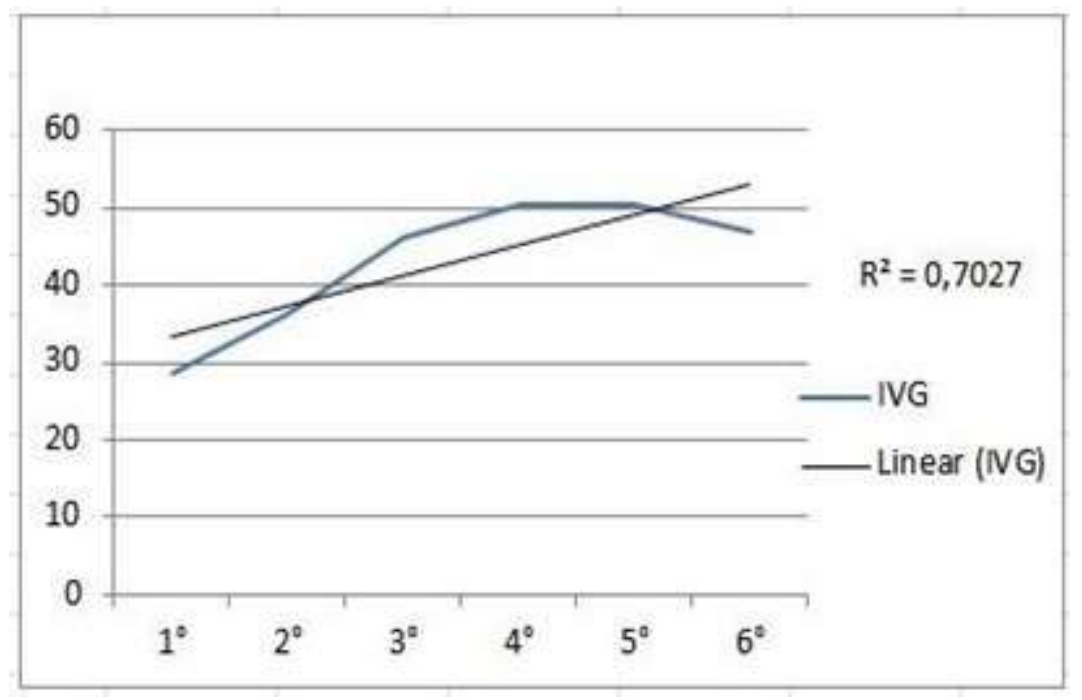

Fonte: Autores.

A Tabela 1 apresenta a análise de variância das variáveis estudadas, calculadas através do teste $* \mathrm{~F}$ a $5 \%$ de probabilidade. A variável diâmetro do caule (DC) apresentou valor significativo pelo teste *F a $1 \%$ de probabilidade. As demais variáveis apresentaram resultado não significativo (NS).

Santos et al. (2020), em sua pesquisa com girassol, utilizando quatro tratamentos: solo sem esterco, solo com esterco bovino, solo com esterco caprino e solo com esterco aviário, onde observaram através do teste F a 5\% de probabilidade que as variáveis altura da planta, tamanho da raiz, diâmetro do caule, massa fresca total e massa seca total tiveram resultados significativos. 
Tabela 1. Resumo da ANOVA (análise de variância) das variáveis nos tratamentos.

\begin{tabular}{lcccccc}
\hline Causas de variação & GL & SQ & QM & F & P & CV\% \\
\hline Altura da planta & 3 & 0,1421 & 0,0474 & $3,1123^{\mathrm{NS}}$ & 0,0558 & 4,78 \\
Diâmetro do caule & 3 & 0,0161 & 0,0054 & $9,8168^{* *}$ & 0,0007 & 7 \\
Número de folhas & 3 & 6910,4 & 2303,5 & $0,7611^{\mathrm{NS}}$ & 0,5322 & 25,055 \\
Massa fresca & 3 & 8,7061 & 2,9020 & $3,0880^{\mathrm{NS}}$ & 0,0570 & 8,6173 \\
Massa seca & 3 & 0,1700 & 0,0567 & $1,0953^{\mathrm{NS}}$ & 0,3797 & 5,6336 \\
Tamanho da raiz & 3 & 0,0179 & 0,0060 & $0,1101^{\mathrm{NS}}$ & 0,9530 & 6,8922 \\
Tamanho total & 3 & 36,936 & 12,312 & $2,2668^{\mathrm{NS}}$ & 2,2668 & 9,6540 \\
\hline
\end{tabular}

GL - grau de liberdade; (SQ) soma dos quadrados; (QM) quadro médio; (P) probabilidade de efeito; (CV) coeficiente de variância;

** significativo a $1 \%$ de probabilidade pelo teste $\mathrm{F}$, * significativo a $5 \%$ de probabilidade pelo teste $\mathrm{F}$ e ${ }^{\text {ns }}=$ não significativo. Fonte:

Autores (2020).

Os dados da Tabela 2, mostram os resultados obtidos através do teste de Tukey a 5\% de probabilidade que houve diferença significativa para o tratamento com esterco caprino, sendo o que apresentou o melhor resultado para a variável diâmetro do caule (DC). Os demais tratamentos não apresentaram diferença significativa.

Segundo Araújo et al. (2010), trabalhando com o esterco caprino, afirmaram que influenciou positivamente no crescimento de mudas de mamoeiro de modo que obteve um resultado superior aos demais tratamentos. Também ouve diferença significativa para o tratamento com o esterco aviário, sendo o que apresentou melhor resultado para a variável mass a fresca (MF), os quatro tratamentos não apresentaram diferenças significativas nas demais variáveis.

Roberto (2019) em sua pesquisa utilizando cinco tratamentos, sendo eles: esterco caprino sem curtir, adubação química, esterco caprino com casca de café, esterco caprino com maravalha e o controle (sem nenhum tipo de adubação), observou que não houve diferença estatística entre os tratamentos com adubos, onde qualquer forma de uso do esterco caprino e a adubação química apresentaram o mesmo resultado no desenvolvimento da Brassica oleracea var. Capitata. Amorim (2002) destaca ainda que, o esterco caprino é um dos melhores para a adubação na agricultura, devido os ricos teores de nitrogênio, fósforo e potássio encontrados.

Silva et al. (2017), observaram em sua pesquisa que a cama de aviário apresentou bom desenvolvimento em número de folhas, altura da planta e diâmetro do caule. Santos et al. (2020), em sua pesquisa com girassol, observaram que as variáveis altura da planta e diâmetro do caule tiveram resultados significativos no tratamento com a utilização de solo com esterco aviário. De acordo com Agnol (2013), o esterco de galinha é rico em nitrogênio, elemento muito importante para o desenvolvimento e produção das plantas.

Tabela 2. Comparação das médias através do teste de Tukey a 5\% de probabilidade dos tratamentos nas variáveis.

\begin{tabular}{|c|c|c|c|c|c|c|c|}
\hline Tratamentos & $\begin{array}{c}\mathbf{A P} \\
(\mathrm{cm})\end{array}$ & $\begin{array}{l}\mathrm{DC} \\
(\mathrm{cm})\end{array}$ & $\begin{array}{l}\mathbf{N F} \\
(\mathbf{U})\end{array}$ & $\begin{array}{r}\text { MF } \\
(\mathbf{g})\end{array}$ & $\begin{array}{c}\text { MS } \\
(\mathrm{g}) \\
\end{array}$ & $\begin{array}{c}\text { TR } \\
(\mathrm{cm})\end{array}$ & $\begin{array}{c}\text { TT } \\
(\mathbf{c m})\end{array}$ \\
\hline Solo + organomineral & $12,28 \mathrm{a}$ & $0,38 \mathrm{bc}$ & $8,6 \mathrm{a}$ & $105 b$ & $53 a$ & $28 \mathrm{a}$ & $58,6 \mathrm{a}$ \\
\hline Solo + aviário & $12,30 \mathrm{a}$ & $0,44 \mathrm{ab}$ & $8,6 \mathrm{a}$ & $158 \mathrm{a}$ & $68 \mathrm{a}$ & $31,8 \mathrm{a}$ & $72,2 \mathrm{a}$ \\
\hline Solo + bovino & $13,32 \mathrm{a}$ & $0,3 \mathrm{c}$ & $8 \mathrm{a}$ & $126 \mathrm{ab}$ & $53 \mathrm{a}$ & $30 \mathrm{a}$ & $67,4 \mathrm{a}$ \\
\hline Solo + caprino & $15,12 \mathrm{a}$ & $0,5 \mathrm{a}$ & $8,14 a$ & $119 \mathrm{ab}$ & $59 a$ & $30 \mathrm{a}$ & $70,6 \mathrm{a}$ \\
\hline
\end{tabular}

Médias seguidas de mesma letra não diferem estatisticamente pelo teste de Tukey no nível de 5\% de significância, (AP) altura da planta, (DC) diâmetro do caule, (NF) número de folhas, (MF) massa fresca, (MS) massa seca, (TR) tamanho da raiz, (TT) tamanho total, (CM) centímetro e (U) unidade. Fonte: Autores (2020).

\section{Conclusão}

As sementes de couve semeadas em substrato de casca de arroz carbonizada obtiveram um bom índice de germinação e de velocidade de germinação. Nos vasos, o tratamento que obteve melhor resultado foi o solo com esterco caprino, seguido 
pelo tratamento com esterco aviário. Devido a necessidade de obter alimentos saudáveis de forma que seja economicamente viável enfatiza-se que existe a necessidade da realização de novos estudos, na busca de fontes alimentares de forma sustentável.

\section{Agradecimentos}

\section{À Universidade Estadual de Alagoas - UNEAL, através do Curso de Ciências Biológicas do Campus I.}

Ao Conselho Nacional de Desenvolvimento Científico e Tecnológico - CNPq, pela bolsa de iniciação à pesquisa.

Ao Grupo de Estudos Ambientais e Etnobiológicos - GEMBIO, pelo apoio logístico, acadêmico e científico para a iniciação à pesquisa.

\section{Referências}

Agnol, S. (2013). Esterco de galinha e seus benefícios. Website Ruralatual. http://ruralatual.blogspot.com.br/2013/08/esterco-de-galinha-e-seusbeneficios.html.

Amorim, A. C. (2002). Caracterização dos dejetos de caprinos: reciclagem energética e de nutrientes. Dissertação (Mestrado) - Curso de Zootecnia, Universidade Estadual Jaboticabal

Araújo, W. B. M. et al. (2010). Esterco caprino na composição de substratos para formação de mudas de mamoeiro. Ciência e Agrotecnologia, $34(1)$, 68-73.

Bezerra Neto, E. et al. (2010). Tratamento de espuma fenólica para produção de mudas de alface. Revista Brasileira de Ciências Agrárias, 5(3).

Barbosa, M. L., P. B. R., \& Almeida P., R. (2021). Aspectos biológicos e produtivos do tomateiro (Solanum lycopersicum) sob adubação húmica: Biological and productive aspects of tomato (Solanum lycopersicum) under humic fertilization. Revista Ambientale, 13(1), 71-78.

Camargo Filho, W. P., \& Camargo, F. P. (2009). Análise das alterações na cadeia de produção de hortaliças em São Paulo. 1995-1997. IEA/CATI. Anuários, banco de dados. www.iea.sp.gov.br.

Dos Santos CabraL, M. J., Pinheiro, R. A., Sousa, T. A.., Silva, J. E., Lima, J. S., \& Barros, R. P. (2019). Características biológicas da cenoura (Daucus carota L., apiaceae) cultivar Brasília em diferentes fontes de matéria orgânica e manejo de irrigação. Revista Ambientale, 11(2), 64-73.

Jordana, F. et al. (2013). A importância da utilização da adubação orgânica na agricultura. Revista Destaques Acadêmicos. CETEC/UNIVATES, 5(4), 327333.

Koch, M., Haubold, B. \& Mitchell-Olds, T. (2001). Molecular systematics of the Brassicaceae: evidence from coding plastidicmatk and nuclear Chs sequences. American Journalof Botany, 88(3), 534-544.

Linhares, P. C. F., Pereira, M. F. S., Moreira, J. C., Paiva, A. C. C., Assis, J. P., \& Sousa, R. P. (2015). Rendimento do coentro (Coriandrum sativum L) adubado com esterco bovino em diferentes doses e tempos de incorporação no solo. Revista Brasileira de Plantas Medicinais, $17,462-467$.

Lunardon, M. T. (2008). Análise da conjuntura agropecuária: agricultura orgânica. Curitiba: Secretaria da Agricultura e do Abastecimento, Departamento de Economia Rural. http://www.agricultura.pr.gov.br/arquivos/File/deral/Prognosticos/agric_organica_0809.pdf..

Maldonado J. W. (2021). AgroEstat Online. http://www.agroestat.com.br.

Paraná. (2018). Secretaria de agricultura e do abastecimento. Centro Paranaense de Referência em Agroecologia-CPRA. Brassica oleracea. http://www.cpra.pr.gov.br/arquivos/File/Brassica_oleracea.pdf.

Roberto, L. A., \& De Paula, L. B. (2019). avaliação agronômica do repolho (Brassica oleracea var. capitata) fertilizado com esterco caprino. In: X Simpósio de Pesquisa e Inovação-2019, Minas Gerais- IF Sudeste MG.

Saidelles, F. L. F. et al. (2009). Casca de arroz carbonizada como substrato para produção de mudas de tamboril-da-mata e garapeira. Carbonized rice hull as substratum to produce tamboril-da-mata and garapeira seedlings. Semina: Ciências Agrárias, Londrina, 30(1), 1173-1186.

Santos, D. R. et al. (2020). Resposta do desempenho da cultura do girassol (Helianthus annuus L., asteraceae) cultivados com esterco aviário em vaso. Revista Ambientale, 12(2), 32-39.

Santos, L. dos, Santos, J. K. B. dos, Santos, E. dos, Santos, T. T. dos, Chagas, A. B., Neves, J. D. S. das, Barros, R. P. de, \& Reis, L. S. (2019). Desenvolvimento de duas variedades de hortaliças da família Solanaceae em solo com diferentes tipos de substratos. Revista Ambientale, 9(1), 1-7.

Silva, D. J. (2017). Monitoramento da couve manteiga (Brassica oleraceae L. var. acephala) cultivada em vasos com diferentes substratos e o registro de pragas-chave. Revista Craibeiras de Agroecologia, 1(1).

Souza, F. C. A. et al. (2014). Produção de mudas de quiabeiro em estufa com diferentes substratos orgânicos. Revista Nucleus, 10(11). $10.3738 / 1982.2278 .1051$.

Souza, R. R., Matias, S. S. R., da Silva, R. R., Silva, R. L., \& Barbosa, J. S. M. (2015). Qualidade de mudas de mamão produzidas em substrato com esterco caprino e doses de superfosfato simples. Revista Agrarian, 8(28), 139-146. 